OPEN ACCESS

Edited by:

Qingshan Wei,

North Carolina State University,

United States

Reviewed by:

Paolo Ugo,

Ca' Foscari University of Venice, Italy

Tae-Hyung Kim,

Chung-Ang University, South Korea

*Correspondence:

Xiuting $\mathrm{Li}$

xiuting.li@szu.edu.cn

Specialty section:

This article was submitted to

Analytical Chemistry,

a section of the journal

Frontiers in Chemistry

Received: 18 June 2020

Accepted: 26 October 2020

Published: 13 November 2020

Citation:

Liu Y, Li X, Chen J and Yuan C (2020) Micro/Nano Electrode Array Sensors:

Advances in Fabrication and Emerging

Applications in Bioanalysis.

Front. Chem. 8:573865.

doi: 10.3389/fchem.2020.573865

\section{Micro/Nano Electrode Array Sensors: Advances in Fabrication and Emerging Applications in Bioanalysis}

\author{
Yang Liu ${ }^{1,2}$, Xiuting $\mathrm{Li}^{1 *}$, Jie Chen ${ }^{1}$ and Chonglin Yuan ${ }^{1}$ \\ ${ }^{1}$ Institute for Advanced Study, Shenzhen University, Shenzhen, China, ${ }^{2}$ College of Physics and Optoelectronic Engineering, \\ Shenzhen University, Shenzhen, China
}

Due to the rapid development of micro/nano manufacturing techniques and the greater understanding in electrochemical principles and methods, micro/nano electrode array sensing has received much attention in recent years, especially in bioanalysis. This review aims to explore recent progress in innovative techniques for the construction of micro/nano electrode array sensor and the unique applications of various types of micro/nano electrode array sensors in biochemical analysis. Moreover, the new area of smart sensing benefited from miniaturization of portable micro/nano electrode array sensors as well as wearable intelligent devices are further discussed.

Keywords: micro/nano electrode array, electrochemical sensor, array sensors fabrication, biological application, smart sensing

\section{INTRODUCTION}

Electrochemical arrays, containing numbers of sensors on single platform or device, are of great interest in electroanalytical chemistry since quantification and characterization of substances in complex sample can be conducted simultaneously with the individual sensors based on electrochemical analysis at high time resolution and sensitivity (LaFratta and Walt, 2008; Chow et al., 2009; Park et al., 2011; Takulapalli et al., 2012; Fu et al., 2016; Li et al., 2019). Electrochemical sensing has a long history since the first electrochemical sensors for oxygen were reported in 1960's and later glucose sensors developed in 2002 (Wang, 2002). Benefited from the great progress made in micro and nano fabrication technology, the field of electrochemical sensing is experiencing a revival (Lemay and White, 2016). Especially in last few years, owing to the rapid development in micro/nano meter scale machining technology, micro/nano electrode array sensors emerged and are constantly receiving great attention because of their multiplexing ability and robustness for bioanalysis at different biological levels (e.g., cell, tissue or organ, etc.) as well as in-situ and real-time dynamic monitoring with higher spatiotemporal resolution and selectivity (Arrigan, 2004; Godino et al., 2009; Ongaro and Ugo, 2013; Liu et al., 2017; Du et al., 2019). Moreover, due to the breakthrough on new materials and microelectronic technology in recent years, micro/mano electrode array sensors are moving toward miniaturization, digitization, intelligence and systematization, and are widely used in diverse fields including environmental monitoring, medical and health care (Feeney and Kounaves, 2000; Berduque et al., 2007; Orozco et al., 2010; Sekretaryova et al., 2015; Liu et al., 2017).

Several reviews have summarized the progresses on micro- or nano-electrode array sensors with concerns for relevant theory, fabrication or application (Arrigan, 2004; Huang et al., 2009; Orozco et al., 2010; Yeh and Shi, 2010; Zoski and Wijesinghe, 2010; Henstridge and Compton, 2012; Chen et al., 2013; Ongaro and Ugo, 2013; Tomćík, 2013; Karimian et al., 2016; Karimian and Ugo, 2019). In this minireview (Figure 1A), we have mainly focused on the recent accomplishments 
in materials and innovative techniques for the construction of various micro/nano electrode array sensors and their unique applications in bioanalysis. In addition, the recent development of smart sensing and wearable intelligent devices benefited from miniaturization of portable micro/nano electrode array sensors are further discussed.

\section{FABRICATION AND CHARACTERISTICS OF MICRO/NANO ELECTRODE ARRAYS}

Single micro/nano electrodes, with dimensions at micro/nano scale, show unique advantages, such as increased mass transport, faster transient response as well as lower destructive probe, compared to conventional electrodes (Penner et al., 1990; Amatore, 1995). A certain number of micro/nano electrodes are arranged and combined to form micro/nano electrode arrays. The electrode size, morphology, structure and material generally determine the electrochemical performance of micro/nano electrode arrays (Arrigan, 2004; Chevallier and Compton, 2007; Hood et al., 2009). Various types of micro/nano electrode arrays adapted to different measuring conditions have been designed and fabricated to meet the sensing requirement. In general, micro/nano electrode arrays could be prepared by means of bottom-up fabrication techniques, mainly involving electrode material (metal, carbon, ceramic, etc.) layer deposition or growth on the top, bottom, or formation in-between sandwich structure relative to the templates or substrates (silicon, glass, polymer, ceramic, etc.) (Patel et al., 2008; Xiang et al., 2009; Lee and Silvester, 2016; Ledo et al., 2017). Photolithography is basic technology commonly applied for micro electrode arrays manufacturing, including surface insulation and micron holes drilling based on parts of thin film or the bulk of a substrate removal selectively by photoresists and illumination sources exposure (Lowinsohn et al., 2006; Aguiar et al., 2007; Ordeig et al., 2008; Xu et al., 2008). Other preparation processes such as screen print, deposition, membrane formation, firing, etc. have also been used for micro electrode arrays fabrication (Mann and Mikkelsen, 2008; Vagin et al., 2014; Lee and Silvester, 2016). In addition, ink-jet and 3D printing technologies have recently become a powerful alternative processing tool for high-resolution microstructures which enables complex electrode patterns at micro scale (Nouran et al., 2018; Kundu et al., 2019). Based on the above various fabrication methods, different types of micro electrode arrays (e.g., microdisk or microband electrode array and interdigitated, linear or 3D micro electrode array, etc.) have been reported (Fiaccabrino et al., 1996; Aguiar et al., 2007; Ordeig et al., 2008; Xu et al., 2008; Menshykau et al., 2010; Yi et al., 2016).

With the breakthrough of nano processing technology and electrochemical instrumentation with higher performance, nano electrode arrays have aroused wider research interests. So far, beside photolithography (Xiang et al., 2009; Chen et al., 2011; Heo et al., 2011), other methods for nano electrode arrays manufacturing, include nanoimprint-lift-off, focused ion beam (FIB), electron beam lithography (EBL) (Sandison and Cooper, 2006; Lanyon and Arrigan, 2007; Errachid et al., 2008; Moretto et al., 2011; Branagan et al., 2012; Ma et al., 2013; Wahl et al., 2013;
Sentic et al., 2016). For example, via FIB milling following by a layer-by-layer deposition, nano electrode arrays on nanochannels with embedded annular nanoband electrodes have been prepared (Branagan et al., 2012).

Nano electrode arrays can be constructed on solid substrates by chemical means, such as template-based method involving electrochemical deposition or chemical plating process (Zhang et al., 2004; Cao and Liu, 2008; Ongaro et al., 2012). In addition, nucleation and growth of materials to form nanostructures with electrochemical performances has also become a way for construction of nano electrode arrays. Vertically aligned carbon nanotubes/nanofibers (Arumugam et al., 2009; Robinson et al., 2016; Song et al., 2019) as well as a vast range of nano electrocatalysts (e.g., prussian blue, porous gold or platinum nanowire, $\mathrm{NiO}$ nanocone, mesoporous rhombus-shaped $\mathrm{ZnO}$ rod, etc.) have been fabricated as nano electrode arrays (Karyakin et al., 2004; Puganova and Karyakin, 2005; Zhang et al., 2009; Wang et al., 2011, 2012; Wen et al., 2015). Different fabrication techniques can be combined to construct more complex nano electrode arrays. For instance, by integrating track-etched polycarbonate membrane and a lithographically fabricated addressable Pt ultramicroelectrode array platform, microregions of a macro-nanoelectrode membrane could be individually addressed (Zoski et al., 2007). Furthermore, an integration scheme for high-density individually and electrically addressable out-of-plane Si nanowire arrays by solid-state wafer bonding were developed for the first time. The fabrication procedures of these new type nano electrode arrays with submicrometer site-tosite spacing mainly involved a combination of photolithography, EBL and plasma enhanced chemical vapor deposition (PECVD) atop an electrically insulating and transparent sapphire substrate with standard integrated circuit fabrication technologies (Liu et al., 2017).

Variety of methods have been developed and employed to achieve electrode arrays characterization at the micron or nano scale, which is helpful for better understanding of electrochemical performance of electrode arrays. Scanning electron microscopy or transmission electron microscopy (SEM, TEM) are commonly used to visualize the dimensions or morphologies of micro/nano electrode arrays (Figure 1B). The topography of the nano electrode arrays is observed by atomic force microscope (AFM) (Puganova and Karyakin, 2005), and in situ AFM technique is even applied to characterize the geometry and surface reactivity variation of electrodes during working in solution (Nogala et al., 2012). X-ray photoelectron spectroscopy (XPS) (Forrer et al., 2000) or energy-dispersive X-ray spectroscopy (EDX) (Liu et al., 2017) normally be used for arrays surface element composition identification (Figure 1B). Additionally, the steady-state limiting current can reflect electrode morphology to some extent (Bond et al., 1988; Arrigan, 2004; Wahl et al., 2013), and the diffusion or reaction layers at nano electrodes arrays can be studied from electrochemical luminescence imaging (Sentic et al., 2016).

Under micro/nano scale sizes, electrode arrays show unique electrochemical characteristics compared with conventional electrodes. As the electrode dimensions decrease to micro/nano scale, the double layer has lower capacitance, and smaller time constant enable micro/nano electrode arrays to achieve rapid 
A

Fabrication and Characteristics

- bottom-up fabrication techniques

- characterization methods

- unique electrochemical characteristics
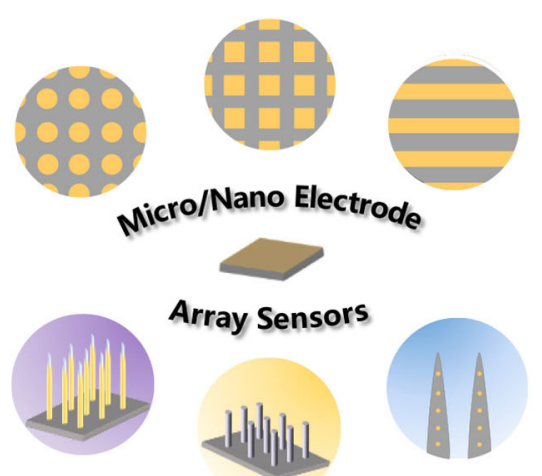

Array Sensors
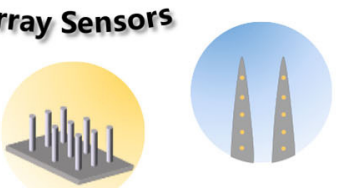

\section{Biological Applications}

- bioactive molecule

- biological macromolecule

- neuroactive substance

- smart sensing

B

a i
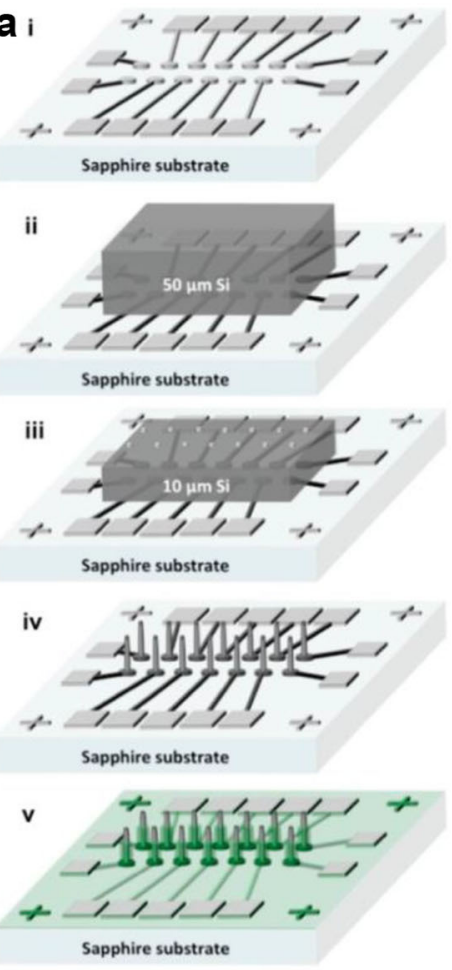
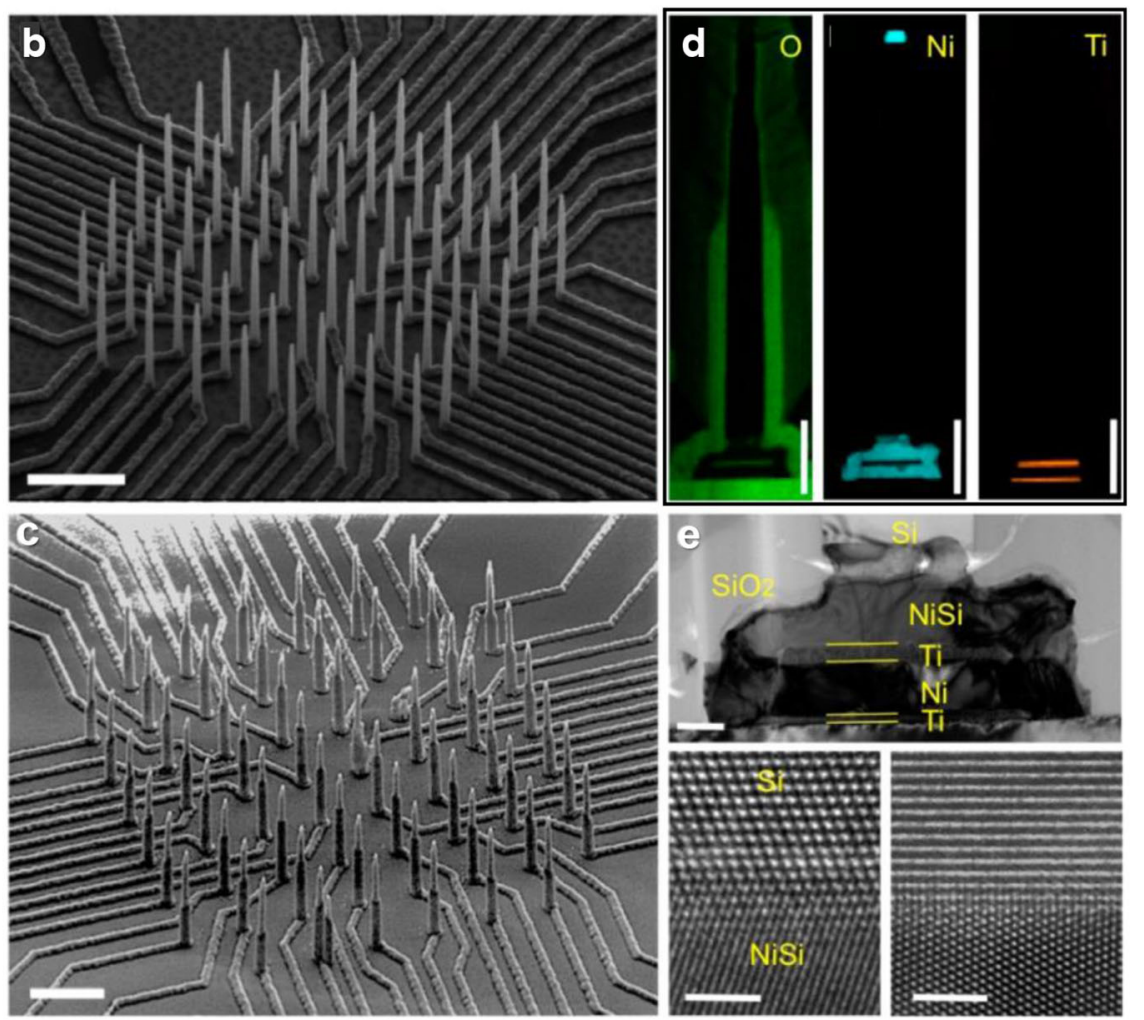

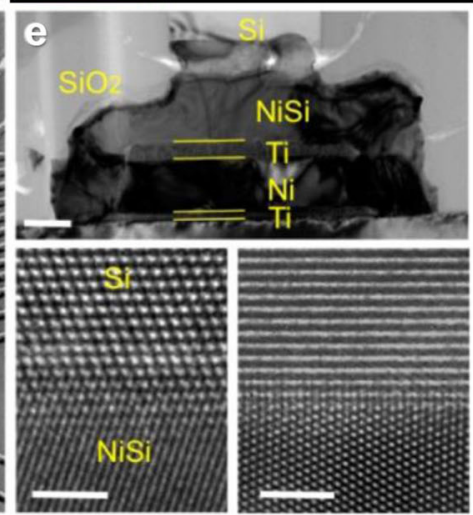

FIGURE 1 | (A) Overview of the main research content on micro/nano electrode array sensors introduced in this minireview. (B) (a) Illustration of fabrication procedure for high density electrically isolated nanowire probes. The SEM images of a typical Si nanowire array (b) after etching and (c) after $\mathrm{SiO}_{2}$ passivation. Scale bar in (b) is $5 \mu \mathrm{m}$ and in (c) is $3 \mu \mathrm{m}$. (d) EDX mapping of $\mathrm{O}, \mathrm{Ni}$, and Ti on single nanowire. Scale bars are $1 \mu \mathrm{m}$. (e) A TEM image of the NiSi/Ti/Ni/Ti underneath the Si nanowire. Scale bar is $200 \mathrm{~nm}$. The bottom panels are HRTEM images at the interface between Si and NiSi. Scale bars in bottom panels are $2 \mathrm{~nm}$. Liu et al. (2017). Copyright ${ }^{\complement}$ 2017 American Chemical Society.

response and high-speed measurement under less destructive sensing (Freeman et al., 2013). Electrode radius becomes smaller than the thickness of diffusion layer for micro/nano electrode arrays, mass transport increases, which is appropriate for the study of electrochemical process transients (Godino et al., 2009; Henstridge and Compton, 2012). For the nano electrode arrays obtained by EBL, important advantages, such as exactly controlled geometry and the miniaturization possibility from pure radial diffusion regime, are showed (Moretto et al., 2011).
The total current generated from micro/nano electrode arrays is the sum of each micro/nano electrodes, resulting in increased detection current, improved signal-to-noise environment and higher analysis sensitivity (Bond et al., 1988; Arrigan, 2004). Furthermore, by electrode modification with specific recognition sites, functional molecules or materials, the stability and selectivity of micro/nano electrode arrays can be improved (Fruk et al., 2007; Arya et al., 2010; Frey et al., 2010; Pang et al., 2017). For instance, as a layered metal oxide semiconductor equipped 
with high work function and good hole conductivity, $\mathrm{MoO}_{3}$ has been electrodeposited successfully on the surfaces of as-prepared

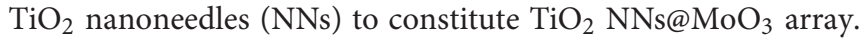
The latter shows ultrasensitive photocurrent response and a wide linear range with a low detection limit on account of tuned interfacial microstructure (Pang et al., 2017). Note that due to the significant increase in mass transfer rate when the size of electrode reaches nano scale, the resulted extreme sensitivity to the electron transfer kinetics may limit their performance in biosensing applications (Menon and Martin, 1995; Sun and Mirkin, 2006; Sliusarenko et al., 2015, 2017; Yu et al., 2016; Edwards et al., 2018).

\section{MICRO/NANO ELECTRODE ARRAY SENSORS FOR BIOLOGICAL APPLICATION}

With the rapid development of science and technology, humans are increasingly focusing on individual health and the impact of environmental conditions on life entities and activities. Over recent decades, studies of bioactive related chemicals (e.g., inorganic salt, neuroactive substances, carbohydrate, nucleic acid, proteins, gas, etc.) have attracted widespread interest due to their crucial roles in a series of physiological and pathological processes, as well as biological applications. Distinguishing characteristics enable micro/nano electrode arrays to act as effective electrochemical sensors for biological application, promoting in vitro and in vivo biosensing research. Various typical applications with micro/nano electrode arrays in bioanalysis are showed in Table 1. Micro/Nano electrode arrays have been applied to electrochemical sensing for bioactive molecule with high sensitivity and selectivity (Puganova and Karyakin, 2005; Burmeister et al., 2008; Xu et al., 2008; Jiang and Zhang, 2009; Arya et al., 2010; Frey et al., 2010; Gholizadeh et al., 2012; Wang et al., 2012; Hinzman et al., 2015; Zhang et al., 2016). Gholizadeh et al. (2012) employed a high-density vertically aligned carbon nanotube nano electrode array (VACNT-NEA) with glutamate dehydrogenase covalently attached on the CNT tips as electrochemical glutamate biosensors, exhibiting an extremely low detection limit of $10 \mathrm{nM}$ for glutamate. A ceramic-based multisite micro electrode array was developed by Burmeister et al. (2008) for simultaneous determinations of choline and acetylcholine in the central nervous system. The array was designed with one recording site modified with choline oxidase (ChOx) and the other with acetylcholinesterase and ChOx. Hinzman et al. (2015) reported the selectively measurement of extracellular adenosine by using an enzyme-linked microelectrode array A in vivo limit of detection leveled down to $\sim 0.04 \mu \mathrm{M}$ is achieved. Moreover, biological macromolecules (e.g., DNA, RNA, protease, etc.) can be detected by micro/nano electrode array sensors (Koehne et al., 2004; Lapierre-Devlin et al., 2005; Periyakaruppan et al., 2013; Silvestrini et al., 2013; Selvam et al., 2015; Lee et al., 2016; Delle et al., 2018; Song et al., 2019). Song et al. (2019) developed vertically aligned carbon nanofibers as unique electrochemical platform for investigating protease activities
(Figure 2A). The carbon nanofibers are functionalized with specific peptide substrates containing a ferrocene tag. It is reported that the detection limit for cathepsin $\mathrm{B}$ activity and concentration are $2.49 \times 10^{-4} \mathrm{~s}^{-1}$ and $0.32 \mathrm{nM}$, respectively. The fabricated nano electrode arrays showed outstanding selectivity with negligible cross-reaction with $6.0 \mathrm{nM}$ of other two cancerrelated proteases (ADAM10 and ADAM17). It demonstrates that the electrochemical chip fabricated with present methodology holds great potential in rapid profiling protease activities in cancer diagnosis. Micro/Nano electrode arrays have been employed as immunosensors, including sensitive detection for immunoglobulin IgY (Bottari et al., 2014), cardiac biomarker (Sharma et al., 2018) and IgG-type tissue transglutaminase (Habtamu et al., 2019), which show the potential to be applied for the diagnosis and monitor of diseases in clinical or nonclinical settings.

Micro/Nano electrode array sensing technology provides an effective tool for neuroactive substances detection and neuron activities direct reading, contributing to reveal the complex neuron communication and connection (Burmeister et al., 2008; Dincer et al., 2015; Liu et al., 2017; Kim et al., 2018; Ledo et al., 2018; Du et al., 2019; Xiao et al., 2019). Kim et al. (2018) developed a simple cylindrical gold nano electrode arrays with optimized electrode size and height for measuring dopamine and detecting its release from human dopaminergic neurons. By modulating the dopamine (DA) concentration, Parkinson's disease (PD) can be well-treated. In order to improve electron transmission capabilities, Xiao et al. (2019) designed a four-shank implantable micro-electrode array with platinum nanoparticles and reduced graphene oxide nanocomposites (Pt/rGO) fabricated onto the recording microelectrode sites. Synchronous DA levels and neural spike real-time detection was achieved in the cortex and caudate putamen during apomorphine modulation of 6-hydroxydopamine-induced Parkinson's disease rats. The changes of ion channel currents and intracellular potentials originated from the ion concentrations differences $\left(\mathrm{Na}^{+}\right.$and $\left.\mathrm{K}^{+}\right)$between the inside and outside of the cell reveal the response of neurons to drugs. Liu et al. (2017) utilized a novel high-density vertical Si nanowire arrays with independent electrical addressability and superior spatial resolution to conduct electrophysiological recordings from mouse and rat primary neurons, as well as human induced pluripotent stem cell-derived neurons (Figure 2B). High signal-to-noise ratios and sensitivity to potentials (as low as a few millivolts) without cell damage was achieved. This new nano electrode arrays is expected to be a platform for drugs screening based on the disease models of neuronal networks, helping to better understand the communication of individual cells in large areas of neural networks and the mechanisms of the drug treatment to neurological diseases.

Owing to the breakthrough in new materials, microelectronic technology as well as electrochemical understandings, biosensors based on micro/nano electrode arrays are moving toward miniaturization, digitization, intelligence and systematization. Smart sensing created from miniaturization of portable micro/nano electrode array sensors as well as wearable intelligent devices has been paid great attention in recent years (Triroj 
TABLE 1 | Micro/Nano electrode arrays for bioanalysis applications.

\begin{tabular}{|c|c|c|c|c|c|}
\hline Electrode array type & Fabrication & Analysis target & Measurement methods & $\begin{array}{l}\text { Sensing } \\
\text { performance }\end{array}$ & References \\
\hline VACNT-NEA & $\begin{array}{l}\text { Photolithography/glutamate } \\
\text { dehydrogenase immobilization }\end{array}$ & Glutamate & $\begin{array}{l}\text { Differential pulse } \\
\text { voltammograms (DPV) }\end{array}$ & $10 \mathrm{nM}(\mathrm{LOD})$ & $\begin{array}{l}\text { Gholizadeh et al., } \\
2012\end{array}$ \\
\hline $\begin{array}{l}\text { Enzyme-linked and } \\
\text { self-referenced } \\
\text { microelectrode arrays }\end{array}$ & $\begin{array}{l}\text { Four Pt recording sites linked } \\
\text { with ADA enzyme/ } \\
\text { micropipette attachment }\end{array}$ & $\begin{array}{l}\text { Extracellular } \\
\text { adenosine }\end{array}$ & $\begin{array}{l}\text { Constant potential } \\
\text { amperometry }\end{array}$ & $0.04 \mu \mathrm{M}$ (in vivo LOD) & Hinzman et al., 2015 \\
\hline $\begin{array}{l}\text { Au-coated vertical silicon } \\
\text { nanowire electrode array } \\
\text { (VSNEA) }\end{array}$ & $\begin{array}{l}\text { Chemical vapor deposition } \\
\text { (CVD)/ peptide immobilization } \\
\text { and RNA functionalization }\end{array}$ & HIV-1 RRE RNA & DPV & 1.513 fM (LOD) & Lee et al., 2016 \\
\hline $\begin{array}{l}\text { Gold nanoscale interdigitated } \\
\text { electrode (IDE) arrays }\end{array}$ & $\begin{array}{l}\text { Nanoimprint and } \\
\text { photolithography }\end{array}$ & DNA hybridization & Impedance spectroscopy & $\begin{array}{l}\text { Dynamic detection } \\
\text { range of } 1-100 \mathrm{nM}\end{array}$ & Delle et al., 2018 \\
\hline $\begin{array}{l}\text { Vertically aligned carbon } \\
\text { nanofibers (VACNFs) arrays }\end{array}$ & $\begin{array}{l}\text { PECVD/passivation and } \\
\text { functionalization of } \\
\text { Fc-hexapeptide substrates }\end{array}$ & $\begin{array}{l}\text { Cathepsin B activity } \\
\text { and concentration }\end{array}$ & AC voltammetry (ACV) & $\begin{array}{l}2.49 \times 10^{-4} \mathrm{~s}^{-1} \text { and } \\
0.32 \mathrm{nM}(\mathrm{LOD})\end{array}$ & Song et al., 2019 \\
\hline $\begin{array}{l}\text { Substrate-bound } \\
\text { interdigitated array (IDA) } \\
\text { nanoelectrodes. }\end{array}$ & $\begin{array}{l}\text { Photolithography and } \\
\text { RF-sputtering/ immobilization } \\
\text { of mAb-cMyo }\end{array}$ & $\begin{array}{l}\text { Cardiac myoglobin } \\
\text { (cMyo). }\end{array}$ & Cyclic voltammetry (CV) & $\begin{array}{l}\text { Linear detection } \\
\text { range of } \\
0.001-100 \mathrm{ng} / \mathrm{mL} \\
0.43 \mathrm{pg} / \mathrm{mL}(\mathrm{LOD})\end{array}$ & Sharma et al., 2018 \\
\hline $\begin{array}{l}\text { Cylindrical gold nano } \\
\text { electrode arrays (CAuNE) }\end{array}$ & $\begin{array}{l}\text { Laser interference lithography } \\
\text { (LIL) and electrochemical } \\
\text { deposition (ECD) }\end{array}$ & $\begin{array}{l}\text { Dopamine (DA) in } \\
\text { human neural cells }\end{array}$ & CV & $5.83 \mu \mathrm{M}(\mathrm{LOD})$ & Kim et al., 2018 \\
\hline $\begin{array}{l}\text { Four-shank implantable } \\
\text { micro-electrode array }\end{array}$ & $\begin{array}{l}\text { Photolithography/ Pt/rGO } \\
\text { nanocomposites modification } \\
\text { onto the recording } \\
\text { microelectrode sites }\end{array}$ & $\begin{array}{l}\text { Synchronous DA } \\
\text { levels and neural } \\
\text { spike real-time } \\
\text { detection }\end{array}$ & Amperometry & $<20 \mathrm{nM}$ (LOD) & Xiao et al., 2019 \\
\hline
\end{tabular}

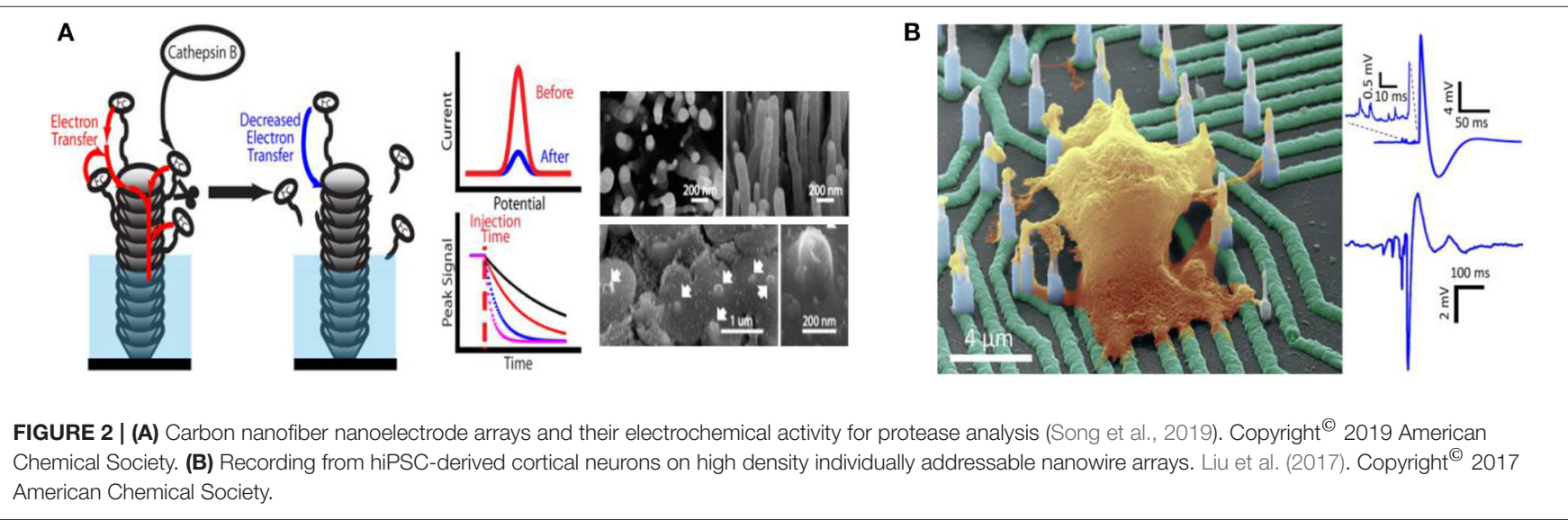

et al., 2011; Huang and Mason, 2013; Wang et al., 2015; Lee et al., 2017; Baradoke et al., 2019; Gao et al., 2019; Kim et al., 2019; Yokus et al., 2020) and proved to possess the capacity to integrate with point-of-care systems. During implantation and long-term conditions, the performance to sample in real time is vital to the effective sensing. Utilizing low density aligned nano electrode arrays as robust transducer elements, Triroj et al. (2011) fabricated a microfluidic biosensor chip with improved sensitivity in a nanoliter volume testbed for the current response by two orders of magnitude compared to that obtained from a microelectrode. The nano electrodes arrays were functionalized with prostate specific antigen (PSA) to construct competitive immunoassay chip, and the detection limit is around
$10 \mathrm{pg} / \mathrm{mL}(\sim 270 \mathrm{fM})$, corresponding to $\sim 30,000$ copies of PSA. An improved sensitive functional system was developed by Wang et al. (2015) for wireless rapid analysis of saxitoxin and brevetoxin with portable cardiomyocyte-based potential biosensor. It was constructed by 8 -channel recording micro electrode arrays, and can dynamically monitor the multisite electrical activity of cardiomyocyte network. Furthermore, a sensor based flexible microneedle electrode array, coupled with a multi-channel portable electrochemical analyzer, was developed by Gao et al. (2019) for the simultaneous detection of glucose, uric acid, and cholesterol levels in serum. Excellent sensing performance with a wide linear range, low detection limit and rapid response time was shown, therefore facilitating effective 
monitoring of blood metabolites at home. Nowadays, portable miniaturization micro/nano electrode arrays and wearable intelligent devices have showed the function of label-free, multiparameter and real-time smart dynamic sensing, which play an important role in both the development of medical devices and biomedical research. In the future, smart sensing created from miniaturized micro/nano electrode array sensors would have broad prospects in biological applications, such as cellular behavior measurement, metabolism monitoring as well as new treatments development.

\section{CONCLUSIONS}

This minireview mainly summarizes the recent advances in fabrication of micro/nano electrode array sensors and presents their emerging biological applications and their use in portable intelligent devices. In past decades, there have been remarkable progresses on the development of micro/nano electrode array sensors for biological applications, however, challenges still present. First, the miniaturized fabrication of micro/nano electrode arrays with more integrating multiplex (e.g., electrooptical response, wearable device) and the development of versatile sensors applicable to the actual conditions. Second, the influence of complex physiological environment in vivo

\section{REFERENCES}

Aguiar, F. A., Gallant, A. J., Rosamond, M. C., Rhodes, A., Wood, D., and Kataky, R. (2007). Conical recessed gold microelectrode arrays produced during photolithographic methods: characterisation and causes. Electrochem. Commun. 9, 879-885. doi: 10.1016/j.elecom.2006.11.023

Amatore, C. (1995). Physical Electrochemistry: Science and Technology, 1st edn. Marcel: Dekker, Inc.

Arrigan, D. W. M. (2004). Nanoelectrodes, nanoelectrode arrays, and their applications. Analyst 129, 1157-1165. doi: 10.1039/b415395m

Arumugam, P. U., Chen, H., Siddiqui, S., Weinrich, J. A., Jejelowo, A., Li, J., et al. (2009). Wafer-scale fabrication of patterned carbon nanofiber nanoelectrode arrays: a route for development of multiplexed, ultrasensitive disposable biosensors. Biosens. Bioelectron. 24, 2818-2824. doi: 10.1016/j.bios.2009.02.009

Arya, S. K., Chornokur, G., Venugopal, M., and Bhansali, S. (2010). Dithiobis (Succinimidyl propionate) modified gold microarray electrode based electrochemical immunosensor for ultrasensitive detection of cortisol. Biosens. Bioelectron. 25, 2296-2301. doi: 10.1016/j.bios.2010.03.016

Baradoke, A., Juodkazyte, J., Masilionis, I., Selskis, A., Pauloukaite, R., and Valiokas, R. (2019). Combined soft lithographic and electrochemical fabrication of nanostructured platinum microelectrode arrays for miniaturized sensor applications. Microelectron. Eng. 208, 39-46. doi: 10.1016/j.mee.2019.02.003

Berduque, A., Lanyon, Y. H., Beni, V., Herzog, G., Watson, Y. E., Rodgers, K., et al. (2007). Voltammetric characterisation of silicon-based microelectrode arrays and their application to mercury-free stripping voltammetry of copper ions. Talanta 71, 102-1030. doi: 10.1016/j.talanta.2006.05.090

Bond, A. M., Luscombe, D., Oldham, K. B., and Zoski, C. G. (1988). A comparison of the chronoamperometric response at inlaid and recessed disc microelectrodes. J. Electroanalyt. Chem. Interf. Electrochem. 249, 1-14. doi: 10.1016/0022-0728(88)80345-0

Bottari, F., Oliveri, P., and Ugo, P. (2014). Electrochemical immunosensor based on ensemble of nanoelectrodes for immunoglobulin IgY detection: application to identify hen's egg yolk in tempera paintings. Biosen. Bioelectron. 52, 403-410. doi: 10.1016/j.bios.2013.09.025 on sensing sensitivity and selectivity remains an issue. Finally, sensing at small amounts of molecules and even exploring the relationship between molecular structure and function are expected eagerly. Finding out solutions to these challenges would be helpful for improving the stability and veracity of the detecting result in quality and quantity, and largely accelerating the wide application of micro/nano electrode array sensors in biological analysis. More importantly, it will greatly promote the understanding of physiological and pathological processes connected with matter in chemical movement, offering a unique contribution to the life related chemicals study and life science research.

\section{AUTHOR CONTRIBUTIONS}

All authors listed have made a substantial, direct and intellectual contribution to the work, and approved it for publication.

\section{FUNDING}

The authors acknowledge the grants from the Natural Science Foundation of SZU (860-000002110386), Regional Joint Fund of Guangdong Province (2019A1515111054), and National Natural Science Foundation of China (22004085).

Branagan, S. P., Contento, N. M., and BohnSean, P. W. (2012). Bohn enhanced mass transport of electroactive species to annular nanoband electrodes embedded in nanocapillary array membranes. J. Am. Chem. Soc. 134, 8617-8624. doi: 10.1021/ja3017158

Burmeister, J. J., Pomerleau, F., Huettl, P., Gash, C. R., Werner, C. E., Bruno, J. P., et al. (2008). Ceramic-based multisite microelectrode arrays for simultaneous measures of choline and acetylcholine in cns. Biosens. Bioelectron. 23, 1382-1389. doi: 10.1016/j.bios.2007.12.013

Cao, G., and Liu, D. (2008). Template-based synthesis of nanorod, nanowire, and nanotube arrays. Adv. Colloid. Interf.Sci. 136, 45-64. doi: 10.1016/j.cis.2007.07.003

Chen, C., Teng, W., and Hahn, J. H. (2011). Nanoband electrode for high-performance in-channel amperometric detection in dual-channel microchip capillary electrophoresis. Electrophoresis 32, 838-843. doi: 10.1002/elps.201000661

Chen, R., Li, Y., Huo, K., and Chu, P. K. (2013). Microelectrode arrays based on carbon nanomaterials: emerging electrochemical sensors for biological and environmental applications. Rsc Adv. 3, 18698. doi: 10.1039/c3ra43033b

Chevallier, F., and Compton, R. (2007). Widening the voltammetric window using regular arrays of microdisk electrodes. Electroanalysis 19, 1741-1745. doi: 10.1002/elan.200703940

Chow, K. F., Mavré, F., Crooks, J. A., Chang, B. -Y., and Crooks, R. M. (2009). A large-scale, wireless electrochemical bipolar electrode microarray. J. Am. Chem. Soc. 131, 8364-8365. doi: 10.1021/ja902683f

Delle, L. E., Pachauri, V., Vlandas, A., Riedel, M., Lägel, B., Lilischkis, R., et al. (2018). Scalable fabrication and application of nanoscale IDE-arrays as multielectrode platform for label-free biosensing. Sens. Actuat. B. 265, 115-125. doi: 10.1016/j.snb.2018.02.174

Dincer, C., Ktaich, R., Laubender, E., Hees, J. J., Kieninger, J., Nebel, C. E., et al. (2015). Nanocrystalline boron-doped diamond nanoelectrode arrays for ultrasensitive dopamine detection. Electrochim. Acta. 185, 101-106. doi: 10.1016/j.electacta.2015.10.113

Du, M. D., Guan, S. L., Gao, L., Lv, S. Y., Yang, S. T., Shi, J. D., et al. (2019). Flexible Micropillar electrode arrays for in vivo neural activity recordings. Small 15:1900582. doi: 10.1002/smll.201900582 
Edwards, M. A., Robinson, D. A., Ren, H., Cheyne, C. G., Tan, C. S., and White, H. S. (2018). Nanoscale electrochemical kinetics and dynamics: the challenges and opportunities of single-entity measurements. Faraday Discuss. 210, 9-28. doi: $10.1039 / \mathrm{C} 8 \mathrm{FD} 00134 \mathrm{~K}$

Errachid, A., Mills, C. A., Pla-Roca, M., Lopez, M. J., Villanueva, G., Bausells, J., et al. (2008). Focused ion beam production of nanoelectrode arrays. Mater. Sci. Eng. C 28, 777-780. doi: 10.1016/j.msec.2007.10.077

Feeney, R., and Kounaves, S. P. (2000). Microfabricated ultramicroelectrode arrays: developments, advances, and applications in environmental analysis. Electroanalysis 12, 677-684. doi: 10.1002/1521-4109(200005)12:9<677::AID-ELAN677>3.0.CO;2-4

Fiaccabrino, G. C., Tang, X. M., Skinner, N., De Rooij, N. F., and KoudelkaHep, M. (1996). Electrochemical characterization of thin-film carbon interdigitated electrode arrays. Analyt. Chim. Acta 326, 155-161. doi: 10.1016/0003-2670(96)00068-2

Forrer, P., Schlottig, F., Siegenthaler, H., and Texor, M. (2000). Electrochemical preparation and surface properties of gold nanowire arrays formed by the template technique. J. Appl. Electrochem. 30, 533-541. doi: 10.1023/A:1003941129560

Freeman, N. J., Sultana, R., Reza, N., Woodvine, H., Terry, J. G., Walton, A. J., et al. (2013). Comparison of the performance of an array of nanoband electrodes with a macro electrode with similar overall area. Phys. Chem. Chem. Phys.15, 8112-8118. doi: 10.1039/c3cp50759a

Frey, O., Holtzman, T., McNamara, R. M., Theobald, D. E. H., van der Wal, P. D., de Rooij, N. F. et al. (2010). Enzyme-based choline and L-glutamate biosensor electrodes on silicon microprobe arrays. Biosens. Bioelectron. 26, 477-484. doi: 10.1016/j.bios.2010.07.073

Fruk, L., Müller, J., Weber, G., Narvaez, A., Dominguez, E., and Niemeyer, C. M. (2007). DNA-directed immobilization of horseradish peroxidase-DNA conjugates on microelectrode arrays: Towards electrochemical screening of enzyme libraries. Chem. Eur. 13, 5223-5231. doi: 10.1002/chem.2006 01793

Fu, K., Han, D., Ma, C., and Bohn, P. W. (2016). Electrochemistry at single molecule occupancy in nanopore-confined recessed ring-disk electrode arrays. Faraday Discuss. 193, 51-64. doi: 10.1039/C6FD00062B

Gao, J., Huang, W., Chen, Z., Yi, C., and Jiang, L. (2019). Simultaneous detection of glucose, uric acid and cholesterol using flexible microneedle electrode array-based biosensor and multi-channel portable electrochemical analyzer. Sens. Actuat. B Chem. 287, 102-110. doi: 10.1016/j.snb.2019. 02.020

Gholizadeh, A., Shahrokhian, S., Iraji Zad, A., Mohajerzadeh, S., Vosoughi, M., Darbari, S., et al. (2012). Fabrication of sensitive glutamate biosensor based on vertically aligned cnt nanoelectrode array and investigating the effect of cnts density on the electrode performance. Anal. Chem. 84, 5932-5938. doi: $10.1021 /$ ac300463x

Godino, N., Borrise, X., Munoz, F. X., del Campo, F. J., and Compton, R. G. (2009). Mass transport to nanoelectrode arrays and limitations of the diffusion domain approach: theory and experiment. J. Phys. Chem. C 113, 11119-11125. doi: $10.1021 /$ jp9031354

Habtamu, H. B., Not, T., De Leo, L., Longo, S., Moretto, L. M., and Ugo, P. (2019). Electrochemical immunosensor based on nanoelectrode ensembles for the serological analysis of IgG-type tissue transglutaminase. Sensors 19:1233. doi: $10.3390 /$ s19051233

Henstridge, M. C., and Compton, R. G. (2012). Mass transport to microand nanoelectrodes and their arrays: a review. Chem. Record 12, 63-71. doi: $10.1002 /$ tcr. 201100032

Heo, J. I., Shim, D. S., Teixidor, G. T., Oh, S., Madou, M. J., and Shin, H. (2011). Carbon interdigitated array nanoelectrodes for electrochemical applications. J. Electrochem. Soc. 158, 76-80. doi: 10.1149/1.3531952

Hinzman, J. M., Gibson, J. L., Tackla, R. D., Costello, M. S., Burmeister, J. J., Quintero, J. E., et al. (2015). Real-time monitoring of extracellular adenosine using enzyme-linked microelectrode arrays. Biosens. Bioelectron. 74, 512-517. doi: 10.1016/j.bios.2015.06.074

Hood, S. J., Kampouris, D. K., Kadara, R. O., Jenkinson, N., del Campo, F. J., Muñoz, F. X., et al. (2009). Why 'the bigger thebetter' is not always the case when utilising microelectrode arrays: high density versus low density arrays for the electroanalytical sensing of chromium (VI). Analyst 134, 2301-2305. doi: $10.1039 /$ b911507b
Huang, X. J., O’ Mahony, A. M., and Compton, R. G. (2009). Microelectrode arrays for electrochemistry: approaches to fabrication. Small 5, 776-788. doi: $10.1002 / \mathrm{smll} .200801593$

Huang, Y., and Mason, A. J. (2013). Lab-on-cmos integration of microfluidics and electrochemical sensors. Lab Chip 13, 3929-3934. doi: 10.1039/c3lc50437a

Jiang, L. C., and Zhang, W. D. (2009). Electrodeposition of $\mathrm{TiO}_{2}$ nanoparticles on multiwalled carbon nanotube arrays for hydrogen peroxide sensing. Electroanalysis 21, 988-993. doi: 10.1002/elan.200804502

Karimian, N., Moretto, L. M., and Ugo, P. (2016). Nanobiosensing with arrays and ensembles of nanoelectrodes. Sensors 17:65. doi: 10.3390/s17010065

Karimian, N., and Ugo, P. (2019). Recent advances in sensing and biosensing with arrays of nanoelectrodes. Curr. Opin. Electrochem. 16, 106-116. doi: 10.1016/j.coelec.2019.04.026

Karyakin, A. A., Puganova, E. A., Budashov, I. A., Kurochkin, I. N., Karyakina, E. E., Levchenko, V.A., et al. (2004). Prussian blue based nanoelectrode arrays for $\mathrm{H}_{2} \mathrm{O}_{2}$ detection. Anal. Chem. 76, 474-478. doi: 10.1021/ac0348591

Kim, D. S., Kang, E. S., Baek, S., Choo, S. S., Chung, Y. H., Lee, D., et al. (2018). Electrochemical detection of dopamine using periodic cylindrical gold nanoelectrode arrays. Sci. Rep. 8:14049. doi: 10.1038/s41598-018-32477-0

Kim, J., Campbell, A. S., de Ávila Berta, E.-F., and Wang, J. (2019). Wearable biosensors for healthcare monitoring. Nat. Biotechnol. 37, 389-406. doi: 10.1038/s41587-019-0045-y

Koehne, J. E., Chen, H., Cassell, A. M., Ye, Q., Han, J., Meyyappan, M., et al. (2004). Miniaturized multiplex label-free electronic chip for rapid nucleic acid analysis based on carbon nanotube nanoelectrode arrays. Clin. Chem. 50, 1886-1893. doi: 10.1373/clinchem.2004.036285

Kundu, A., Nattoo, C., Fremgen, S., Springer, S., Ausaf, T., and Rajaraman, S. (2019). Optimization of makerspace microfabrication techniques and materials for the realization of planar, $3 \mathrm{~d}$ printed microelectrode arrays in under four days. RSC Adv. 9, 8949-8963. doi: 10.1039/C8RA09116A

LaFratta, C. N., and Walt, D. R. (2008). Very High density sensing arrays. Chem. Rev. 108, 614-637. doi: 10.1021/cr0681142

Lanyon, Y. H., and Arrigan, D. W. M. (2007). Recessed nanoband electrodes fabricated by focused ion beam milling. Sens. Actuat. B Chem. B 121, 341-347. doi: 10.1016/j.snb.2006.11.029

Lapierre-Devlin, M. A., Asher, C. L., Taft, B. J., Gasparac, R., Roberts, M. A., and Kelley, S. O. (2005). Amplified electrocatalysis at DNA-modified nanowires. Nano Lett. 5, 1051-1055. doi: 10.1021/nl050483a

Ledo, A., Lourenço, C. F., Laranjinha, J., Brett, C. M. A., Gerhardt, G. A., and Barbosa, R. M. (2017). Ceramic-based multisite platinum microelectrode arrays: morphological characteristics and electrochemical performance for extracellular oxygen measurements in brain tissue. Anal. Chem. 89, 1674-1683. doi: 10.1021/acs.analchem.6b03772

Ledo, A., Lourenço, C. F., Laranjinha, J., Gerhardt, G. A., and Barbosa, R. M. (2018). Concurrent measurements of neurochemical and electrophysiological activity with microelectrode arrays: new perspectives for constant potential amperometry. Curr. Opin. Electrochem. 12, 129-140. doi: 10.1016/j.coelec.2018.05.018

Lee, J., Hong, M. H., Han, S., Na, J., Kim, I., Kwon, Y. J., et al. (2016). Sensitive and selective detection of HIV-1 RRE RNA using vertical silicon nanowire electrode array. Nanoscale Res Lett. 11, 341-347. doi: 10.1186/s11671-016-1504-8

Lee, J., and Silvester, D. S. (2016). Low-cost microarray thin-film electrodes with ionic liquid gel-polymer electrolytes for miniaturised oxygen sensing. Analyst 141, 3705-3713. doi: 10.1039/C6AN00281A

Lee, W., Kim, D., Matsuhisa, N., Nagase, M., Sekino, M., Malliaras, G. G., et al. (2017). Transparent, conformable, active multielectrode array using organic electrochemical transistors. Proc. Natl. Acad. Sci. U. S. A. 114, 10554-10559. doi: $10.1073 /$ pnas. 1703886114

Lemay, S., and White, H. (2016). Electrochemistry at the nanoscale: tackling old questions, posing new ones. Acc. Chem. Res. 49:2371. doi: 10.1021/acs.accounts.6b00515

Li, Z., Askim, J. R., and Suslick, K. S. (2019). The optoelectronic nose: colorimetric and fluorometric sensor arrays. Chem. Rev. 119, 231-292. doi: 10.1021/acs.chemrev.8b00226

Liu, R., Chen, R., Elthakeb, A. T., Lee, S. H., Hinckley, S., Khraiche, M. L. (2017). High density individually addressable nanowire arrays record intracellular activity from primary rodent and human stem cell derived neurons. Nano Lett. 17, 2757-2764. doi: 10.1021/acs.nanolett.6b04752 
Lowinsohn, D., Peres, H. E. M., Kosminsky, L., Paixao, T., Ferreira, T. L., RamirezFernandez, F. J., et al. (2006). Design and fabrication of a microelectrode array for iodate quantification in small sample volumes. Sens. Actuat. B 113, 80-87. doi: $10.1016 /$ j.snb.2005.02.024

Ma, C., Contento, N. M., Gibson, L. R., and Bohn, P. W. (2013). Redox cycling in nanoscale-recessed ring-disk electrode arrays for enhanced electrochemical sensitivity. ACS Nano. 7, 5483-5490. doi: 10.1021/nn401542x

Mann, T. S., and Mikkelsen, S. R. (2008). Antibiotic susceptibility testing at a screen-printed carbon electrode array. Anal. Chem. 80, 843-848. doi: $10.1021 /$ ac701829c

Menon, V. P., and Martin, R. (1995). Fabrication and evaluation of nanoelectrode ensembles. Anal. Chem. 67, 1920-1928. doi: 10.21236/ADA293465

Menshykau, D., O’Mahony, A. M., Cortina-Puig, M., Campo, F. J. D., Muñozb, F. X., and Compton, R. G. (2010). Chronoamperometry on ring, ringrecessed and disk electrodes, and their arrays. The sensitive measurement of diffusion coefficients independent of a knowledge of concentration or number of electrons transferred. J. Electroanal. Chem. 647, 20-28. doi: 10.1016/j.jelechem.2010.05.018

Moretto, L. M., Tormen, M., De Leo, M., Carpentiero, A., and Ugo, P. (2011). Polycarbonate-based ordered arrays of electrochemical nanoelectrodes obtained by e-beam lithography. Nanotechnology. 22:185305. doi: 10.1088/0957-4484/22/18/185305

Nogala, W., Velmurugan, J., and Mirkin, M. V. (2012). Atomic force microscopy of electrochemical nanoelectrode. Anal. Chem. 84, 5192-5197. doi: $10.1021 /$ ac $300744 \mathrm{t}$

Nouran, A., Sabrina, W., Silke, S., Brings, F., Yakushenko, A., Offenhäusser, A., et al. (2018). Printed microelectrode arrays on soft materials: from PDMS to hydrogels. NPJ Flex. Electron. 2, 15. doi: 10.1038/s41528-018-0027-z

Ongaro, M., Gambirasi, A., Favaro, M., and Ugo, P. (2012). Electrochemical synthesis and characterization of hierarchically branched $\mathrm{ZnO}$ nanostructures on ensembles of gold nanowires. Electrochim. Acta. 78, 539-546. doi: 10.1016/j.electacta.2012.06.077

Ongaro, M., and Ugo, P. (2013). Bioelectroanalysis with nanoelectrode ensembles and arrays. Anal. Bioanal. Chem. 405, 3715-3729. doi: 10.1007/s00216-012-6552-z

Ordeig, O., Godino, N., del Campo, J., Munoz, F. X., Nikolajeff, F., and Nyholm, L. (2008). On-chip electric field driven electrochemical detection using a poly(dimethylsiloxane) microchannel with gold microband electrodes. Anal. Chem. 80, 3622-3632. doi: 10.1021/ac702570p

Orozco, J., Fernández-Sánchez, C., and Jiménez-Jorquera, C. (2010). Ultramicroelectrode array based sensors: a promising analytical tool for environmental monitoring. Sensors 10, 475-490. doi: 10.3390/s100100475

Pang, X., Bian, H., Su, M., Ren, Y., Qi, J., Ma, H., et al. (2017). Photoelectrochemical cytosensing of RAW264.7 macrophage cells based on a TiO2 Nanoneedls@MoO3 array. Anal. Chem. 89, 7950-7957. doi: 10.1021/acs.analchem.7b01038

Park, J. H., Hwang, S., and Kwak, J. (2011). Ordered polymeric microhole array made by selective wetting and applications for electrochemical microelectrode array. Langmuir 27, 8548-8553. doi: 10.1021/la2011698

Patel, B. A., Arundell, M., Quek, R. G. W., Harvey, S. L., Ellis, I. R., Florence, M. M., et al. (2008). Individually addressable microelectrode array for monitoring oxygen and nitric oxide release. Anal. Bioanal. Chem. 390, 1379-1387. doi: 10.1007/s00216-007-1803-0

Penner, R. M., Heben, M. J., Longin, T. L., and Lewis, N. S. (1990). Fabrication and use of nanometer-sized electrodes in electrochemistry. Science 250, 1118-1121. doi: $10.1126 /$ science. 250.4984 .1118

Periyakaruppan, A., Gandhiraman, R. P., Meyyappan, M., and Koehne, J. E. (2013). Label-free detection of cardiac troponin-i using carbon nanofiber based nanoelectrode arrays. Anal. Chem. 85, 3858-3863. doi: 10.1021/ac30 $2801 z$

Puganova, E. A., and Karyakin, A. A. (2005). New materials based on nanostructured prussian blue for development of hydrogen peroxide sensors. Sens. Actuat. B Chem. B 109, 167-170. doi: 10.1016/j.snb.2005.03.094

Robinson, J. E., Heineman, W. R., Sagle, L. B., Meyyappan, M., and Koehne, J. E. (2016). Electrochemical characterization of vertically aligned carbon nanofiber arrays prepared by hole-mask colloidal lithography. Electroanalysis 28, 3039-3047. doi: 10.1002/elan.201600303
Sandison, M. E., and Cooper, J. M. (2006). Nanofabrication of electrode arrays by electron-beam and nanoimprint lithographies. Lab. Chip. 6, 1020-1025. doi: $10.1039 / \mathrm{b} 516598 \mathrm{a}$

Sekretaryova, A. N., Eriksson, M., and Turner, A. P. F. (2015). Bioelectrocatalytic systems for health applications. Biotechnol. Adv. 34, 177-197. doi: 10.1016/j.biotechadv.2015.12.005

Selvam, A. P., Prasad, S., Barrett, T. W., and Kazmierczak, S. C. (2015). Electrical nanowell diagnostics sensors for rapid and ultrasensitive detection of prostatespecific antigen. Nanomedicine 10, 2527-2536. doi: 10.2217/nnm.15.100

Sentic, M., Virgilio, F., Zanut, A., Manojlovic, D., Arbault, S., Tormen, M., et al. (2016). Microscopic imaging and tuning of electrogenerated chemiluminescence with boron-doped diamond nanoelectrode arrays. Anal. Bioanal. Chem. 408, 7085-7094. doi: 10.1007/s00216-016-9504-1

Sharma, D., Lee, J., and Shin, H. (2018). An electrochemical immunosensor based on a $3 \mathrm{D}$ carbon system consisting of a suspended mesh and substrate-bound interdigitated array nanoelectrodes for sensitive cardiac biomarker detection. Biosens. Bioelectron. 107, 10-16. doi: 10.1016/j.bios.2018.02.010

Silvestrini, M., Fruk, L., and Ugo, P. (2013). Functionalized ensembles of nanoelectrodes as affinity biosensors for DNA hybridization detection. Biosens. Bioelectron. 40, 265-270. doi: 10.1016/j.bios.2012.07.041

Sliusarenko, O. Y., Oleinick, A. I., Svir, I. B., and Amatore, C. A. (2015). Development and validation of an analytical model for predicting chronoamperometric responses of random arrays of micro- and nanodisk electrodes. Chem. Electr. Chem. 2, 1279-1291. doi: 10.1002/celc.201500222

Sliusarenko, O. Y., Oleinick, A. I., Svir, I. B., and Amatore, C. A. (2017). Importance of stochastic limitations in electrochemistry at arrays of nanoelectrodes functionalized by redox self-assembled monolayers. Russ. J. Electrochem. 53, 1019-1028. doi: 10.1134/S1023193517090129

Song, Y., Fan, H., Anderson, M. J., Wright, J. G., Hua, D. H., Koehne, J., et al. (2019). An electrochemical activity assay for protease analysis using carbon nanofiber nanoelectrode arrays. Anal. Chem. 91, 3971-3979. doi: 10.1021/acs.analchem. 8 b05189

Sun, P., and Mirkin, M. V. (2006). Kinetics of electron-transfer reactions at nanoelectrodes. Anal. Chem. 78, 6526-6534. doi: 10.1021/ac060924q

Takulapalli, B. R., Qiu, J.i, Magee, D. M., Kahn, P., Brunner, A., Barker, K., et al. (2012). High density diffusion-free nanowell arrays. J. Prot. Res. 11, 4382-4391. doi: $10.1021 / \mathrm{pr} 300467 \mathrm{q}$

Tomćík, P. (2013). Microelectrode arrays with overlapped diffusion layers as electroanalytical detectors: theory and basic applications. Sensors 13, 13659-13684. doi: 10.3390/s131013659

Triroj, N., Jaroenapibal, P., Shi, H., Yeh, J. I., and Beresford, R. (2011). Microfluidic chip-based nanoelectrode array as miniaturized biochemical sensing platform for prostate-specific antigen detection. Biosens. Bioelectron. 26, 2927-2933. doi: 10.1016/j.bios.2010.11.039

Vagin, M. Y., Sekretaryova, A. N., Reategui, R. S., Lundstrom, I., Winquist, F., and Eriksson, M. (2014). Arrays of screen-printed graphite microband electrodes as a versatile electroanalysis platform. ChemElectroChem 1, 755-762. doi: 10.1002/celc.201300204

Wahl, A., Dawson, K., MacHale, J., Barry, S., Quinn, A. J., and O'Riordan, A. (2013). Gold nanowire electrodes in array: simulation study and experiments. Faraday Discuss. 164, 377-390. doi: 10.1039/c3fd00025g

Wang, J. (2002). Glucose biosensors: 40 years of advances and challenges. Electroanalysis 10, 107-119. doi: 10.1002/1521-4109(200108)13:12<983::AID-ELAN983>3.0.CO;2-\%23

Wang, X. H., Yang, Z., Sun, X. L., Li, X. W., Wang, D. S., Wang, P., et al. (2011). $\mathrm{NiO}$ nanocone array electrode with high capacity and rate capability for Li-ion batteries. J. Mater. Chem. 21, 9988-9990. doi: 10.1039/c1jm11490e

Wang, Y., Zhu, Y., Chenb, J., and Zeng, Y. (2012). Amperometric biosensor based on 3D ordered freestanding porous Pt nanowire array electrode. Nanoscale 4, 6025-6031. doi: 10.1039/c2nr31256e

Wang,Q., Fang, J., Cao, D., Li, H., Su, K., Hu, N., et al. (2015). An improved functional assay for rapid detection of marine toxins, saxitoxin and brevetoxin using a portable cardiomyocyte-based potential biosensor. Biosen. Bioelectron. 72, 10-17. doi: 10.1016/j.bios.2015.04.028

Wen, Z., Zhu, L., Zhang, Z., and Ye, Z. (2015). Fabrication of gas sensor based on mesoporous rhombus-shaped $\mathrm{ZnO}$ rod arrays. Sens. Actuat. B Chem. 208, 112-121. doi: 10.1016/j.snb.2014.11.024 
Xiang, C. X., Yang, Y. G., and Penner, R. M. (2009). Cheating the diffraction limit: electrodeposited nanowires patterned by photolithography. Chem. Commun. 2009, 859-873. doi: 10.1039/b815603d

Xiao, G., Song, Y., Zhang, Y., Xu, S., Xing, Y., Wang, M., et al. (2019). Platinum/Graphene oxide coated microfabricated arrays for multinucleus neural activities detection in the rat models of parkinson's disease treated by apomorphine. ACS Appl. Bio Mater. 2, 4010-4019. doi: 10.1021/acsabm.9b00541

Xu, H., Malladi, K., Wang, C., Kulinsky, L., Song, M., and Madou, M. (2008). Carbon post-microarrays for glucose sensors. Biosens. Bioelectron. 23, 1637-1644. doi: 10.1016/j.bios.2008.01.031

Yeh, J. I., and Shi, H. (2010). Nanoelectrodes for biological measurements. Wiley Interdiscip. Rev. Nanomed. Nanobiotechnol. 2, 176-188. doi: 10.1002/wnan.70

Yi, W., Yang, Y., Hashemi, P., and Cheng, M. M.-C. (2016). 3D carbon nanofiber microelectrode arrays fabricated by plasma-assisted pyrolysis to enhance sensitivity and stability of real-time dopamine detection. Biomed. Microdevices 18, 112. doi: 10.1007/s10544-016-0136-1

Yokus, M. A., Songkakul, T., Pozdin, V. A., Bozkurt, A., and Daniele, M. A. (2020). Wearable multiplexed biosensor system toward continuous monitoring of metabolites. Biosens. Bioelectron. 153, 112038. doi: 10.1016/j.bios.2020.112038

Yu, Y., Sun, T., and Mirkin, M. V. (2016). Toward more reliable measurements of electron-transfer kinetics at nanoelectrodes: next approximation. Anal. Chem.88, 11758-11766. doi: 10.1021/acs.analchem.6b03392

Zhang, M., Lenhert, S., Wang, M., Chi, L., Lu, N., Fuchs, H., et al. (2004). Regular arrays of copper wires formed by template-assisted electrodeposition. Adv. Mater.16, 409-413. doi: 10.1002/adma.200305577
Zhang, X., Li, D., Bourgeois, L., Wang, H., and Webley, P. A. (2009). Direct electrodeposition of porous gold nanowire arrays for biosensing applications. ChemPhysChem. 10, 436-441. doi: 10.1002/cphc.200800538

Zhang, Y., Zhou, Q., Zhao, W., Chu, W., and Zheng, J. (2016). Array of recessed gold nanoelectrodes formed withn polymethylmethacrylate for individual detection of ascorbic acid, dopamine and uric acid. Electrochim. Acta. 212, 25-31. doi: 10.1016/j.electacta.2016.06.126

Zoski, C. G., and Wijesinghe, M. (2010). Electrochemistry at ultramicroelectrode arrays and nanoelectrode ensembles of macro- and ultramicroelectrode dimensions. Isr. J. Chem. 50, 347-359. doi: 10.1002/ijch.2010 00025

Zoski, C. G., Yang, N., He, P., Berdondini, L., and Koudelka-Hep, M. (2007). Addressable nanoelectrode membrane arrays: fabrication and steady-state behavior. Anal. Chem. 79, 1474-1484. doi: 10.1021/ac06 19534

Conflict of Interest: The authors declare that the research was conducted in the absence of any commercial or financial relationships that could be construed as a potential conflict of interest.

Copyright (C) $2020 \mathrm{Liu}, \mathrm{Li}$, Chen and Yuan. This is an open-access article distributed under the terms of the Creative Commons Attribution License (CC BY). The use, distribution or reproduction in other forums is permitted, provided the original author(s) and the copyright owner(s) are credited and that the original publication in this journal is cited, in accordance with accepted academic practice. No use, distribution or reproduction is permitted which does not comply with these terms. 